\title{
Effect of Alginate and Chitosan Edible Coating Enriched with Olive Leaves Extract on the Shelf Life of Sweet Cherries (Prunus avium L.)
}

\author{
Wissam Zam \\ Al-Andalus University for Medical Sciences, Faculty of Pharmacy, Department of Analytical and Food Chemistry, Tartous, Syria \\ Correspondence should be addressed to Wissam Zam; ws.sarah2005@gmail.com
}

Received 25 May 2019; Revised 26 June 2019; Accepted 11 July 2019; Published 24 July 2019

Guest Editor: Tomy J. Gutiérrez

Copyright ( $\odot 2019$ Wissam Zam. This is an open access article distributed under the Creative Commons Attribution License, which permits unrestricted use, distribution, and reproduction in any medium, provided the original work is properly cited.

\begin{abstract}
Edible film coatings are widely used as a protective barrier for the reduction of transpiration and respiration, therefore reducing the ripening process in fruits and vegetables and improving their quality. The influence of chitosan $1 \%$ and alginate $3 \%$ enriched with olive leaves extract (OLE) on the quality of sweet cherries was studied. Overall, the ripening process and the increase in anthocyanins were found to be delayed with the use of coating particularly those composed of chitosan in combination with OLE. Ascorbic acid and total phenolic contents were recorded with restricted loss at the end of 20 days of storage in both chitosan- and alginate-coated samples enriched with OLE. Higher values of antioxidant activity expressed as the percentage inhibition of DPPH were reported in correlation with phytochemical content. It could be concluded that chitosan and alginate coating enriched with OLE could be efficient for prolonging the shelf life of sweet cherries.
\end{abstract}

\section{Introduction}

Sweet cherry (Prunus avium L.) is one of the most appreciated fruits by consumer due to its high content in essential dietary components and is mainly consumed as not processed. Healthpromoting effects related to its content in phytochemicals such as ascorbic acid, anthocyanins, and phenolic compounds are recently proved by many epidemiological studies [1]. However, sweet cherries deteriorate rapidly after harvest due to the high respiration rate and metabolic activities which result in a decrease in acidity and phytochemical content, weight loss, and change in color and total soluble content [2].

Recently, the preservation of fruit quality and the increase of their shelf life are maintained by the use of edible coatings which could retard some physiological processes such as respiration and transpiration [3]. Generally, film from polysaccharides such as alginate and chitosan, proteins, and lipids are commercially used and could be applied to protect the whole fruit [4].

Chitosan is a high-molecular-weight carbohydrate polymer produced by the deacetylation of chitin [5]. It is widely applied in the storage of fruits and vegetables as a semipermeable film that regulates the internal atmosphere and reduces the transpiration, thus extending their shelf life [5]. Results of different studies proved that the application of chitosan was effective in retarding the ripening process of strawberries [6], sweet cherries [7], papaya [3], and carambola [8].

Alginate is a natural polysaccharide extracted from brown seaweeds from the family of Phaeophyceae. It has several film-forming properties such as transparency and uniformity and serves as an excellent barrier to moisture [9]. In particular, alginate has unique colloidal properties allowing its use as a thickening agent and a stabilizing material [10]. It is widely used to enhance the shelf life of many fruits and vegetables by reducing dehydration, controlling respiration, and improving mechanical properties [11]. Several studies reported the use of alginate for delaying the ripening process of tomato [12], pineapples [13], watermelon [14], and sweet cherries [15].

A wide variety of natural extracts and essential oils could be used to enrich the edible coating in order to enhance their 
properties [16]. Chitosan enriched with pomegranate peel extract and moringa leaf extract was found to be more effective in maintaining the fruit quality of guava and avocado [17]. The shelf life of "Newhall" navel orange was extended by the use of chitosan coating enriched with hairy fig (Ficus hirta Vahl.) fruit extract [18]. Alginate coating enriched with grapefruit seed extract showed a good preservation of antioxidant activity and antifungal effect on grapes [19].

Olive leaves (Olea europaea L.) are considered as a potential source of several bioactive compounds mainly a wide number of phenolic compounds of diverse nature [20]. Olive leaf extract (OLE) is known to possess high antioxidant and antimicrobial activities and therefore is effective against several diseases such as coronary disease, diabetes, and some bacterial infections [21]. Therefore, the addition of olive leaves extract into edible coating materials could possibly improve the phytochemical status and the shelf life of sweet cherries.

Several previous researchers used different polymers for prolonging the shelf life of sweet cherries including chitosan and alginate. However, to the best of our knowledge, there is no report on the use of chitosan or alginate enriched with olive leaves extract on the ripening process of sweet cherries and their phytochemical status during storage. Therefore, the aim of this study was to evaluate the effect of the addition of olive leaves extract to chitosan or alginate on the postharvest quality of sweet cherries during 20 days of storage. Based on previous researches dealing with film-based coating for the maintenance of fruit quality, the hypothesis of our research is that the addition of OLE will improve the properties of chitosan and alginate film coatings.

\section{Materials and Methods}

2.1. Plant Material and Experimental Design. Sweet cherries (Prunus avium L., Bigarreau Burlat cultivar) were brought from the local fruit market of Tartous city. Fruits were selected at commercial maturity stage, free from any diseases or physical injuries. They were sorted for uniform size, shape, and color.

The selected fruits were washed with water and dipped in $1 \%$ sodium hypochlorite for $10 \mathrm{~min}$ and then air-dried. After complete drying, fruits were grouped into 5 sets and immersed in the film solutions for two minutes to assure the uniformity of the coating of the whole surface as follows: (1) $3 \%$ alginate, (2) $1 \%$ chitosan, (3) $3 \%$ alginate $+1 \%$ OLE, (4) $1 \%$ chitosan $+1 \%$ OLE, and (5) distilled water as control. The coated fruits were dried for 30 min under air-flow heater at $25^{\circ} \mathrm{C}$, packed in plastic boxes, and stored at room temperature $\left(25 \pm 5^{\circ} \mathrm{C}\right.$ and $65 \pm 5 \%$ relative humidity). Fifteen fruits were analyzed in triplicate at an interval of 4 days till 20 days of storage as the fruit became unacceptable for consumption due to decay or infection.

2.2. Preparation of Edible Coatings. Sodium alginate powder (Sigma-Aldrich) was dissolved in distilled hot water $\left(45^{\circ} \mathrm{C}\right)$ at a concentration of $3 \%(\mathrm{w} / \mathrm{v})$. After cooling, $10 \%$ glycerol and $2 \%(\mathrm{w} / \mathrm{v})$ calcium chloride solution were added to the alginate solution as a plasticizer and a firming agent, respectively [17].

One gram of chitosan (Sigma-Aldrich) was dispersed in $100 \mathrm{~mL}$ aqueous solution of glacial acetic acid $(0.5 \% \mathrm{v} / \mathrm{v})$ with constant agitation at room temperature for $1 \mathrm{~h}$ to obtain complete dispersion [20]. The $\mathrm{pH}$ value was adjusted to 5.6 with $1 \mathrm{M} \mathrm{NaOH}$, and glycerol $(0.75 \%)$ was added as plasticizer.

Olive leaves extract was prepared by mixing $2 \mathrm{~g}$ of grounded leaves with $100 \mathrm{~mL}$ of $40 \%$ ethanol at $60^{\circ} \mathrm{C}$ for $120 \mathrm{~min}$. The extract was centrifuged at $5000 \mathrm{rpm}$ for 5 minutes. The supernatant was concentrated using rotary evaporator at $40^{\circ} \mathrm{C}$. This OLE was incorporated at $1 \%$ level in chitosan and alginate solutions [20].

2.3. Fruit Weight Loss. Weight loss was determined in each set by the following equation [22]:

$$
\text { Weight loss }(\%)=\frac{w 0-w 1}{w 0} * 100 \text {, }
$$

where $w 0$ is the initial weight of fruit samples and $w 1$ is the weight of fruit samples at each storage period. The weight loss was expressed as the percentage loss compared with the initial weight.

2.4. Total Soluble Solids and Titratable Acidity. Cherry juice was extracted from 3 fruit samples and filtered. Total soluble solids (TSS) were measured according to AOAC using an Abbe 3-L refractometer and reported as ${ }^{\circ} \mathrm{Brix}$ [23]. Titratable acidity (TA) was measured by $\mathrm{NaOH}(0.1 \mathrm{~N})$ and expressed as $\mathrm{g}$ of malic acid equivalent per $100 \mathrm{~g}$ fresh weight [24].

2.5. Ascorbic Acid Content. Determination of ascorbic acid in the sample was made by 2,6-dichloroindophenol titrimetric method (AOAC Method 967.21). First, the fruit extract was prepared by maceration using 3\% metaphosphoric acid $\left(\mathrm{HPO}_{3}\right)$. Then, the prepared extract was filtered and titrated with 2,6-dichloroindophenol until the rose pink color persisted for 15-20 s [25]. The ascorbic acid content was expressed as mg per $100 \mathrm{~g}$ fresh weight.

2.6. Antioxidant Activity, Total Phenolics, and Anthocyanins Determination. To evaluate the antioxidant activity of cherry fruit during the storage period, the method of 2,2diphenyl-1-picrylhydrazyl (DPPH) was used [26]. For the preparation of cherry extracts, samples of $5 \mathrm{mg}$ in $20 \mathrm{~mL}$ of methanol were homogenized and placed in an ultrasonic bath for $30 \mathrm{~min}$ at $4^{\circ} \mathrm{C}$ and centrifuged. The supernatant was filtered, and $3.9 \mathrm{~mL}$ of $\mathrm{DPPH}$ was added to $0.1 \mathrm{~mL}$ of the extract. After an incubation period of $60 \mathrm{~min}$, in a dark room, the absorbance of the mixture was measured at $520 \mathrm{~nm}$ using a Shimadzu UV-vis double-beam spectrophotometer and methanol as blank. Radical scavenging activity was expressed as the percentage inhibition of DPPH radical.

The same methanol extract was also used for total phenolic content determination using Folin-Ciocalteu 
method. To $0.1 \mathrm{~mL}$ of the sample, $0.5 \mathrm{~mL}$ of $1 \mathrm{~N}$ FolinCiocalteu reagent, $2.9 \mathrm{~mL}$ distilled water, and $2 \mathrm{~mL} \mathrm{Na} 2 \mathrm{CO} 3$ (20\%) were added. The mixture was incubated for $30 \mathrm{~min}$ in a water bath at $40^{\circ} \mathrm{C}$. The absorbance was taken at $734 \mathrm{~nm}$ using a UV-visible spectrophotometer. Total phenolic content was calculated in terms of $\mathrm{mg}$ of gallic acid equivalent per $100 \mathrm{~g}$ fresh weight of the sample.

The anthocyanin content was quantified according to the method of Serrano et al. [27]. $5 \mathrm{~mL}$ of the methanol extract was loaded onto preconditioned C18 Sep-Pak cartridge and eluted using acidified $\mathrm{MeOH}(0.01 \% \mathrm{HCl})$. The absorbance of the collected fractions was performed at $530 \mathrm{~nm}$, and the anthocyanin was expressed as cyanidin-3-glucoside equivalent (molecular weight of $449.2 \mathrm{~g} / \mathrm{mol}$ and molar absorption coefficient of $23900 \mathrm{l} / \mathrm{cm} \cdot \mathrm{mol}$ ), and the results were expressed as $\mathrm{mg} / 100 \mathrm{~g}$.

2.7. Statistical Study. Data are expressed as the mean$\mathrm{s} \pm$ standard deviation. To determine the difference between uncoated and coated fruits in each sample, one-way ANOVA test was used and differences at $p<0.05$ were considered significant.

\section{Results and Discussion}

Weight loss increased during storage, reaching values of $9.63 \pm 0.12 \%$ in control fruit after 20 days. The weight loss was significantly lower at $8.83 \pm 0.21 \%, 7.75 \pm 0.08 \%$, $6.13 \pm 0.26 \%$, and $5.35 \pm 0.17 \%$ in samples coated with alginate, alginate + OLE, chitosan, and chitosan + OLE, respectively. This weight loss is correlated with an increase in water loss due to rise in transpiration and respiration [19]. This could be explained by the high surface/volume ratio in sweet cherries and their low skin diffusion resistance [28]. Similar results were reported in previous studies with other edible coatings and concluded that edible films created a physical barrier against moisture loss and reduced the transpiration rate [29].

As presented in Table 1, the TSS at harvest was $17.83 \pm 1.26^{\circ} \mathrm{Brix}$ and this value increased slightly during storage probably due to the water loss, activity of hydrolytic enzymes, or the decrease in respiration rate and conversion of sugars in $\mathrm{CO}_{2}$ and $\mathrm{H}_{2} \mathrm{O}$ during the storage period [30]. After 20 days of storage, the lowest $\left(18.62 \pm 0.46^{\circ} \mathrm{Brix}\right)$ and highest $\left(19.16 \pm 0.49^{\circ} \mathrm{Brix}\right)$ amounts of TSS were related to chitosan-OLE and control samples, respectively, with no significant differences $(p>0.05)$. Nabifarkhani et al. [31] found same results for sweet cherries coated by chitosan and thyme oils. Our results are also consistent with those of other studies for other fruits such as strawberries, guava, mango, and banana $[7,32]$.

Titratable acidity estimates the organic acid content of fruit which generally decreases during postharvest storage due to the use of organic acids as substrates for respiratory metabolism [33]. As noticed in Table 1, TA decreased during storage time in both uncoated and coated fruit samples, but this decrease was less noticeable in coated fruit. The lower acidity loss in chitosan-coated fruit during storage was also reported in other studies on sweet cherries, guava, and strawberry $[7,32]$. Same results were previously found for fruit coated with alginate [22]. Nair et al. [17] also confirmed that the decrease in TA occurred at a slower rate in guava fruit coated by chitosan or alginate in combination with pomegranate peel extract. The same results were found for blueberries coated by chitosan enriched with Aloe vera [34].

Overall, the ripening process in sweet cherries was found to be slightly retarded with the use of film coating particularly chitosan in combination with olive leaves extract. Similar results have been reported in case of guava coated with chitosan enriched by pomegranate peel extract [17], blueberries coated with chitosan in combination with Aloe vera extract [34], and mandarin coated with alginate in combination with Ficus hirta fruit extract [18].

Ascorbic acid is a potent free radical scavenger that prevents the degradation of fruit during the ripening process [35]. As noticed in Figure 1, the content of ascorbic acid had no significant difference $(p>0.05)$ between different samples during the storage time. In contrast, it was previously found that the application of chitosan coatings enriched with pomegranate peel extract on guava decreased the loss of ascorbic acid during storage [17]. Similar results of delay in ascorbic acid in chitosan-coated sweet cherries were reported by Dang et al. [36] who hypothesized that coating materials lowered the oxygen permeability and the activity of enzymes resulting in the prevention of the oxidative deterioration of ascorbic acid.

Phenolic compounds are secondary metabolites, which are produced in many plants through phenylpropanoid metabolization. They possess potent free radical scavenging activity, could chelate metal ions, and modulate some enzymes activity [37]. Figure 2 represents the changes in total phenolic content in sweet cherries samples during storage using different coating materials. All fruit samples showed an increase in phenolic compounds concentration during the first 8 days of storage followed by a decline in concentrations until the end of storage attributed to the activity of peroxidase and polyphenol oxidase enzymes $[3,15,19]$. Coated fruit exhibited a lower rate of decrease in total phenolic content values compared with uncoated fruit probably due to lower permeability of oxygen and thereby lower activity of enzymes [38]. Significant difference $(p<0.05)$ in total phenolic content was found between samples coated with edible coatings enriched by OLE and control. The maximum retention of phenolic compounds was observed in both chitosan- and alginate-coated samples enriched with OLE (90.98\% and $90.79 \%$, respectively), followed by chitosan- and alginate-coated samples $(76.87 \%$ and $75.04 \%$, respectively). Previous studies demonstrated that the loss of phenolic compounds could be restricted as effect of coating in various fruits such as guava coated with chitosan enriched by pomegranate peel extract [17] and strawberries coated with alginate in combination with antimicrobial agents [37].

Anthocyanins, one of the major groups of flavonoids, are natural water-soluble pigments connected with ripening stage of the fruit and mainly used as an indicator of cherry quality [39]. The concentration and distribution of 
TABLE 1: Total soluble solids and titratable acidity of uncoated and coated fruits after 20 days of storage.

\begin{tabular}{|c|c|c|c|}
\hline & Days & Total soluble solids ( $\left.{ }^{\circ} \mathrm{Brix}\right)$ & Titratable acidity $(\mathrm{mg} / 100 \mathrm{~g})$ \\
\hline \multirow{3}{*}{ Control } & 0 & $17.83^{\mathrm{b}} \pm 1.26$ & $0.51^{\mathrm{a}} \pm 0.04$ \\
\hline & 8 & $18.32^{\mathrm{a}} \pm 0.58$ & $0.46^{\mathrm{a}} \pm 0.09$ \\
\hline & 20 & $19.16^{\mathrm{a}} \pm 0.49$ & $0.39^{\mathrm{b}} \pm 0.06$ \\
\hline \multirow{3}{*}{ Alginate coating } & 0 & $17.83^{\mathrm{b}} \pm 1.26$ & $0.51^{\mathrm{a}} \pm 0.04$ \\
\hline & 8 & $18.29^{\mathrm{a}} \pm 0.76$ & $0.46^{\mathrm{a}} \pm 0.13$ \\
\hline & 20 & $19.05^{\mathrm{a}} \pm 0.63$ & $0.41^{\mathrm{b}} \pm 0.09$ \\
\hline \multirow{3}{*}{ Alginate + olive leaves extract (OLE) coating } & 0 & $17.83^{\mathrm{b}} \pm 1.26$ & $0.51^{\mathrm{a}} \pm 0.04$ \\
\hline & 8 & $18.22^{\mathrm{a}} \pm 0.39$ & $0.47^{\mathrm{a}} \pm 0.03$ \\
\hline & 20 & $18.93^{\mathrm{a}} \pm 0.96$ & $0.42^{\mathrm{b}} \pm 0.10$ \\
\hline \multirow{3}{*}{ Chitosan coating } & 0 & $17.83^{\mathrm{b}} \pm 1.26$ & $0.51^{\mathrm{a}} \pm 0.04$ \\
\hline & 8 & $18.30^{\mathrm{a}} \pm 1.03$ & $0.48^{\mathrm{a}} \pm 0.11$ \\
\hline & 20 & $18.88^{\mathrm{a}} \pm 0.56$ & $0.43^{\mathrm{a}} \pm 0.06$ \\
\hline \multirow{3}{*}{ Chitosan + OLE coating } & 0 & $17.83^{\mathrm{b}} \pm 1.26$ & $0.51^{\mathrm{a}} \pm 0.04$ \\
\hline & 8 & $18.14^{\mathrm{a}} \pm 0.79$ & $0.49^{\mathrm{a}} \pm 0.12$ \\
\hline & 20 & $18.62^{\mathrm{a}} \pm 0.46$ & $0.46^{\mathrm{a}} \pm 0.04$ \\
\hline
\end{tabular}

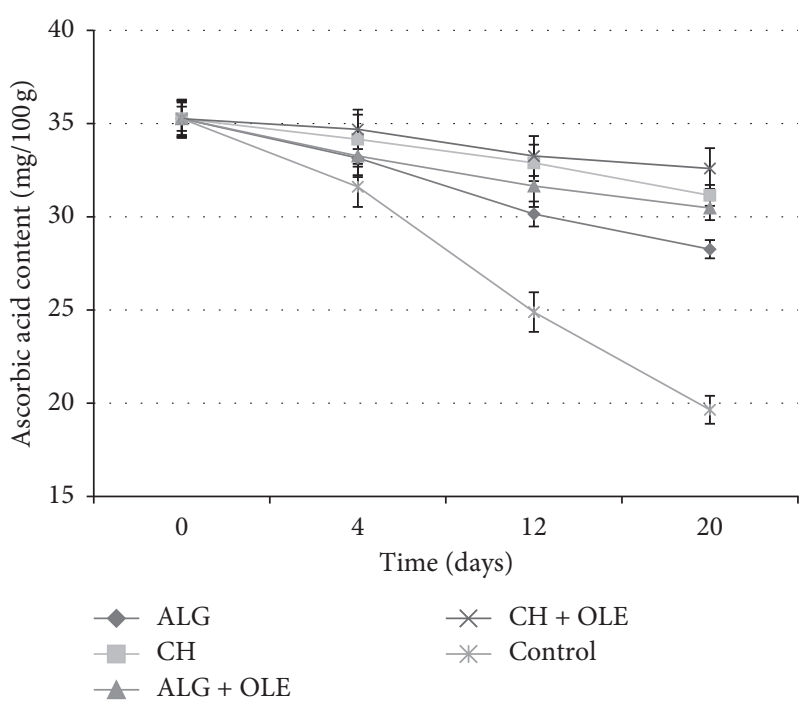

FIGURE 1: Ascorbic acid content during storage expressed as $\mathrm{mg} /$ $100 \mathrm{~g}$ fresh weight. ALG: $3 \%$ alginate, $\mathrm{CH}: 1 \%$ chitosan, ALG + OLE: $3 \%$ alginate $+1 \%$ olive leaves extract (OLE), $\mathrm{CH}+$ OLE: $1 \%$ chitosan $+1 \%$ OLE, and control: distilled water.

cyanidin-3-O-glucoside and cyanidin-3-O-rutinoside in the skin mainly influence the color of cherries. As can be seen in Figure 3, anthocyanins increased during the storage period as ripening progressed. After harvest, the total anthocyanin content was $23.65 \pm 2.65 \mathrm{mg} / 100 \mathrm{~g}$. Significant difference $(p<0.05)$ in the anthocyanin content was only reported for samples coated with chitosan enriched by OLE compared with control samples. At the end of storage period, the lowest $(32.76 \pm 3.15 \mathrm{mg} / 100 \mathrm{~g})$ and highest $(43.26 \pm 65 \mathrm{mg} / 100 \mathrm{~g})$ amounts of anthocyanin were related to chitosan enriched with OLE and control samples, respectively. The increase of anthocyanins after harvest has been previously reported for cherries [15] and other fruits such as strawberries and pomegranate and may be pertained to the anthocyanin synthesis in the fruit during storage [33]. As shown in Figure 3, the dense structure of edible film coating

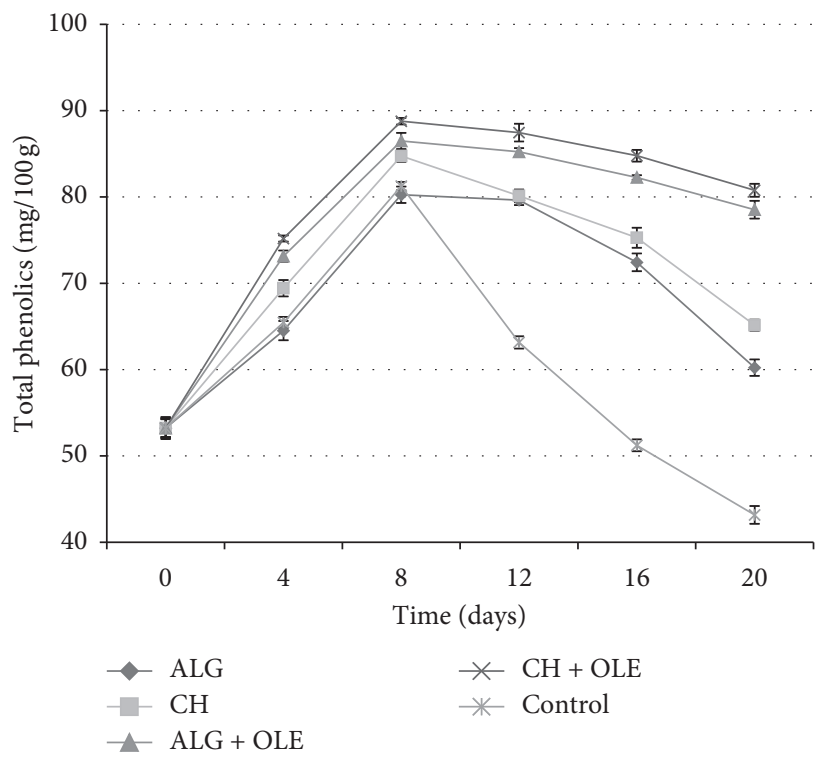

FIgURE 2: Total phenolic content during storage expressed as mg of gallic acid equivalent per $100 \mathrm{~g}$ fresh weight of the sample. ALG: $3 \%$ alginate, $\mathrm{CH}$ : $1 \%$ chitosan, ALG + OLE: $3 \%$ alginate $+1 \%$ olive leaves extract (OLE), $\mathrm{CH}+$ OLE: $1 \%$ chitosan $+1 \%$ OLE, and control: distilled water.

reduced the increase of anthocyanins, probably due to changes in the fruit internal atmosphere.

In the present study, the antioxidant activity (AOA) expressed as the percentage inhibition of $\mathrm{DPPH}$ radicals increased slightly in cherry fruit within the first four days and subsequently decreased in all samples, with significant differences only showed for samples coated with chitosan enriched by OLE (Figure 4). The increase in AOA could be partially due to the internal atmosphere modification caused by edible coatings which results in the initial accumulation of phenolic compounds [40]. Alginate coating was found to improve the AOA in coated Ficus hirta fruit and grapefruits $[19,38]$. Petriccione et al. [33] reported an increase in the AOA in chitosan-coated strawberry fruit within the first six days. This behavior might also be explained by the Maillard 


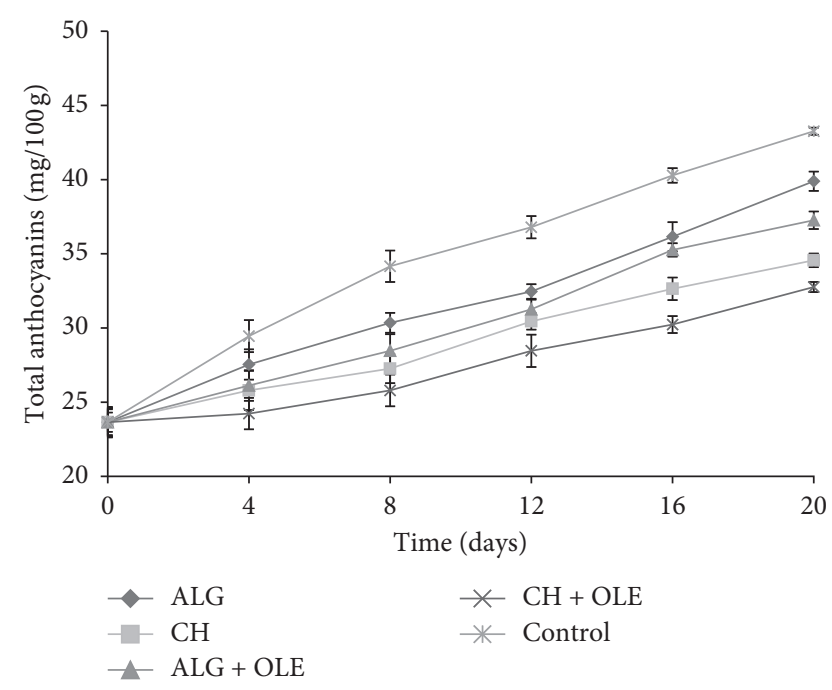

Figure 3: Changes in total anthocyanins expressed as mg cyanidin3 -glucoside equivalent per $100 \mathrm{~g}$ fresh weight of the sample. ALG: $3 \%$ alginate, $\mathrm{CH}: 1 \%$ chitosan, ALG + OLE: $3 \%$ alginate $+1 \%$ olive leaves extract (OLE), $\mathrm{CH}+\mathrm{OLE}$ : $1 \%$ chitosan $+1 \%$ OLE, and control: distilled water.

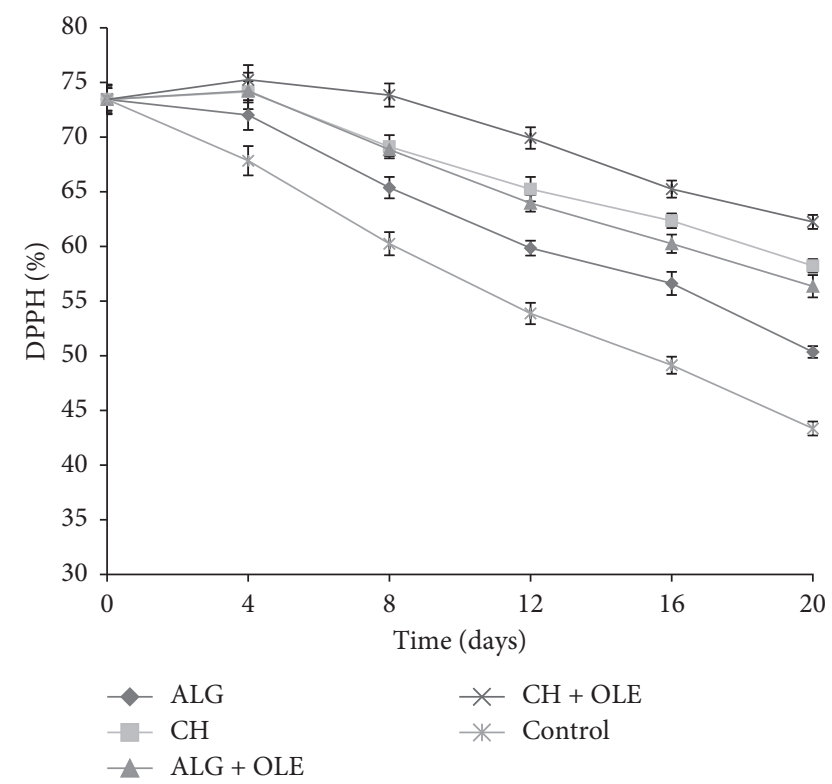

FIgURE 4: Changes in antioxidant activity expressed as the percentage inhibition of DPPH radical. ALG: $3 \%$ alginate, $\mathrm{CH}: 1 \%$ chitosan, ALG + OLE: $3 \%$ alginate $+1 \%$ olive leaves extract (OLE), $\mathrm{CH}+$ OLE: $1 \%$ chitosan $+1 \%$ OLE, and control: distilled water.

reaction associated with the formation of brown melanoidins with high AOA [41]. The highest AOA was recorded in case of coated samples with chitosan $(62.25 \pm 2.35 \%$ and $58.23 \pm 3.64 \%$ for chitosan + OLE and chitosan, respectively), followed by alginate coating $(56.36 \pm 3.12 \%$ and $50.35 \pm 2.67 \%$ for alginate + OLE and alginate, respectively), whereas the lowest AOA was recorded for control samples $(43.35 \pm 3.45 \%)$ after 20 days of storage.
Finally, we were able to prove that our hypothesis about the improvement of chitosan and alginate film coatings properties by the addition of OLE was right.

\section{Conclusion}

Edible coating containing natural extracts has been widely used for extending the shelf life of fruits and vegetables. The present study found for the first time that the use of olive leaves extract in combination with chitosan or alginate has a positive influence on the physicochemical traits of the sweet cherries. They were proved to retard the ripening process of sweet cherries with a maximum retention of phenolic compounds compared with uncoated fruit samples. Moreover, the retention of phytochemicals was correlated with better antioxidant capacity in samples coated with chitosan enriched by OLE. Further researches should be followed in order to determine other properties of coatings developed from various polysaccharides enriched with olive leaves extract such as antibacterial activities and to extend the work on other fruits and vegetables.

\section{Data Availability}

The data used to support the findings of this study are available from the corresponding author upon request.

\section{Conflicts of Interest}

The authors declare that there are no conflicts of interest.

\section{Acknowledgments}

This work was funded by the Al-Andalus University for Medical Sciences.

\section{References}

[1] G. Ferretti, T. Bacchetti, A. Belleggia, and D. Neri, "Cherry antioxidants: from farm to table," Molecules, vol. 15, no. 10, pp. 6993-7005, 2010.

[2] J. Alonso and R. Alique, "Influence of edible coating on shelf life and quality of "Picota" sweet cherries," European Food Research and Technology, vol. 218, no. 6, pp. 535-539, 2004.

[3] A. Ali, M. T. M. Muhammad, K. Sijam, and Y. Siddiqui, "Effect of chitosan coatings on the physicochemical characteristics of Eksotika II papaya (Carica papaya L.) fruit during cold storage," Food Chemistry, vol. 124, no. 2, pp. 620-626, 2011.

[4] C. Chen, X. Peng, R. Zeng, M. Chen, C. Wan, and J. Chen, "Ficus hirta fruits extract incorporated into an alginate-based edible coating for Nanfeng mandarin preservation," Scientia Horticulturae, vol. 202, pp. 41-48, 2016.

[5] F. Varasteh, K. Arzani, M. Barzegar, and Z. Zamani, "Pomegranate (Punica granatum L.) fruit storability improvement using pre-storage chitosan coating technique," Journal of Agricultural Science and Technology, vol. 19, no. 2, pp. 389-400, 2017.

[6] K. Martínez, M. Ortiz, A. Albis, C. Gilma Gutiérrez Castañeda, M. Valencia, and C. G. Tovar, "The effect of edible chitosan coatings incorporated with Thymus capitatus 
essential oil on the shelf-life of strawberry (fragaria $x$ ananassa) during cold storage," Biomolecules, vol. 8, no. 4, p. 155, 2018.

[7] M. Petriccione, F. De Sanctis, M. S. Pasquariello et al., "The effect of chitosan coating on the quality and nutraceutical traits of sweet cherry during postharvest life," Food and Bioprocess Technology, vol. 8, no. 2, pp. 394-408, 2015.

[8] N. B. Gol, M. L. Chaudhari, and T. V. R. Rao, "Effect of edible coatings on quality and shelf life of carambola (Averrhoa carambola L.) fruit during storage," Journal of Food Science and Technology, vol. 52, no. 1, pp. 78-91, 2015.

[9] P. C. Koh, M. A. Noranizan, Z. A. Nur Hanani, R. Karim, and S. Z. Rosli, "Application of edible coatings and repetitive pulsed light for shelf life extension of fresh-cut cantaloupe (Cucumis melo L. reticulatus cv. Glamour)," Postharvest Biology and Technology, vol. 129, pp. 64-78, 2017.

[10] C. A. Acevedo, D. A. López, M. J. Tapia et al., "Using RGB image processing for designing an alginate edible film," Food and Bioprocess Technology, vol. 5, no. 5, pp. 1511-1520, 2012.

[11] T. S. Parreidt, K. Müller, and M. Schmid, "Alginate-based edible films and coatings for food packaging applications," Foods, vol. 7, no. 10, p. 170, 2018.

[12] P. J. Zapata, F. Guillén, D. Martínez-Romero, S. Castillo, D. Valero, and M. Serrano, "Use of alginate or zein as edible coatings to delay postharvest ripening process and to maintain tomato (Solanum lycopersicon Mill) quality," Journal of the Science of Food and Agriculture, vol. 88, no. 7, pp. 1287-1293, 2008.

[13] N. Azarakhsh, A. Osman, H. M. Ghazali, C. P. Tan, and N. Mohd Adzahan, "Optimization of alginate and gellan-based edible coating formulations for fresh-cut pineapples," International Food Research Journal, vol. 19, no. 1, pp. 279-285, 2012.

[14] E. Poverenov, R. Cohen, T. Yefremov, Y. Vinokur, and V. Rodov, "Effects of polysaccharide-based edible coatings on fresh-cut melon quality," Acta Horticulturae, vol. 1015, no. 1015, pp. 145-151, 2014.

[15] V. Chiabrando and G. Giacalone, "Effects of alginate edible coating on quality and antioxidant properties in sweet cherry during postharvest storage," Italian Journal of Food Science, vol. 27, no. 2, pp. 173-180, 2015.

[16] R. K. Dhall, "Advances in edible coatings for fresh fruits and vegetables: a review," Critical Reviews in Food Science and Nutrition, vol. 53, no. 5, pp. 435-450, 2013.

[17] M. S. Nair, A. Saxena, and C. Kaur, "Effect of chitosan and alginate based coatings enriched with pomegranate peel extract to extend the postharvest quality of guava (Psidium guajava L.)," Food Chemistry, vol. 240, pp. 245-252, 2018.

[18] C. Chen, N. Cai, J. Chen, X. Peng, and C. Wan, "Chitosanbased coating enriched with hairy fig (Ficus hirta Vahl.) fruit extract for "newhall" navel orange preservation," Coatings, vol. 8, no. 12, p. 445, 2018.

[19] H. Aloui, K. Khwaldia, L. Sánchez-González et al., “Alginate coatings containing grapefruit essential oil or grapefruit seed extract for grapes preservation," International Journal of Food Science \& Technology, vol. 49, no. 4, pp. 952-959, 2014.

[20] W. Zam, A. Ali, and R. Hasan, "Optimization of extraction conditions for the recovery of phenolic compounds and antioxidants from Syrian olive leaves," Journal of Pharmacognosy and Phytochemistry, vol. 5, no. 5, pp. 390-394, 2016.

[21] O. M. M. Sabry, "Review: beneficial health effects of olive leaves extracts," Journal of Natural Sciences Research, vol. 4, no. 19, 2014.

[22] R. Lim, C. E. Stathopoulos, and J. B. Golding, "Effect of edible coatings on some quality characteristics of sweet cherries,"
International Food Research Journal, vol. 18, no. 4, pp. 1237-1241, 2011.

[23] Association of Official Analytical Chemists, Official Methods of Analysis, Association of Official Analytical Chemists, Washington, DC, USA, 18th edition, 2005.

[24] M. Siddiq, A. Iezzoni, A. Khan et al., "Characterization of new tart cherry (Prunus cerasus L.): selections based on fruit quality, total anthocyanins, and antioxidant capacity," International Journal of Food Properties, vol. 14, no. 2, pp. 471-480, 2011.

[25] AOAC, "Vitamin C (ascorbic acid) in vitamin preparations and juices, official method 967.21," in Official Methods of Analysis, , AOAC International, Washington, DC, USA, 13th edition, 1990.

[26] W. Brand-Williams, M. E. Cuvelier, and C. Berset, "Use of a free radical method to evaluate antioxidant activity," LWT-Food Science and Technology, vol. 28, no. 1, pp. 25-30, 1995.

[27] M. Serrano, F. Guillén, D. Martínez-Romero, S. Castillo, and D. Valero, "Chemical constituents and antioxidant activity of sweet cherry at different ripening stages," Journal of Agricultural and Food Chemistry, vol. 53, no. 7, pp. 2741-2745, 2005.

[28] A. A. Wani, P. Singh, K. Gul, M. H. Wani, and H. C. Langowski, "Sweet cherry (Prunus avium): critical factors affecting the composition and shelf life," Food Packaging and Shelf Life, vol. 1, no. 1, pp. 86-99, 2014.

[29] M. Shamloo, M. Sharifani, A. D. Gramakhany, and E. Seifie, "Alternation of flavonoid compounds in Valencia Orange fruit (Citrus sinensis) peel as a function of storage period and edible covers," Minerva Biotecnologica, vol. 25, pp. 191-197, 2013.

[30] E. Comabella and I. Lara, "Cell wall disassembly and postharvest deterioration of "sweetheart" sweet cherry fruit: involvement of enzymic and non-enzymic factors," Pure and Applied Chemical Sciences, vol. 1, no. 1, pp. 1-18, 2013.

[31] N. Nabifarkhani, M. Sharifani, A. Daraei Garmakhany, E. Ganji Moghadam, and A. Shakeri, "Effect of nano-composite and Thyme oil (Tymus Vulgaris L) coating on fruit quality of sweet cherry (Takdaneh Cv) during storage period," Food Science \& Nutrition, vol. 3, no. 4, pp. 349-354, 2015.

[32] S. P. Singh and R. K. Pal, "Controlled atmosphere storage of guava (Psidium guajava L.) fruit," Postharvest Biology and Technology, vol. 47, no. 3, pp. 296-306, 2008.

[33] M. Petriccione, F. Mastrobuoni, M. S. Pasquariello et al., "Effect of chitosan coating on the postharvest quality and antioxidant enzyme system response of strawberry fruit during cold storage," Foods, vol. 4, no. 4, pp. 501-523, 2015.

[34] J. M. Vieira, M. L. Flores-López, D. J. de Rodríguez, M. C. Sousa, A. A. Vicente, and J. T. Martins, "Effect of chitosan-Aloe vera coating on postharvest quality of blueberry (Vaccinium corymbosum) fruit," Postharvest Biology and Technology, vol. 116, pp. 88-97, 2016.

[35] A. E. Al-Snafi, "Medicinal plants with antioxidant and free radical scavenging effects (part 2): plant based review," IOSR Journal of Pharmacy, vol. 6, no. 7, pp. 62-82, 2016.

[36] Q. F. Dang, J. Q. Yan, Y. Li, X. J. Cheng, C. S. Liu, and X. G. Chen, "Chitosan acetate as an active coating material and its effects on the storing of Prunus avium L," Journal of Food Science, vol. 75, no. 2, pp. 125-131, 2010.

[37] G. Peretto, W.-X. Du, R. J. Avena-Bustillos, J. D. J. Berrios, P. Sambo, and T. H. McHugh, "Electrostatic and conventional spraying of alginate-based edible coating with natural antimicrobials for preserving fresh strawberry quality," Food and Bioprocess Technology, vol. 10, no. 1, pp. 165-174, 2017. 
[38] S. Y. Wang and H. Gao, "Effect of chitosan-based edible coating on antioxidants, antioxidant enzyme system, and postharvest fruit quality of strawberries (Fragaria $x$ aranassa Duch.)," LWT-Food Science and Technology, vol. 52, no. 2, pp. 71-79, 2013.

[39] M. J. Serradilla, M. Lozano, M. J. Bernalte, M. C. Ayuso, M. López-Corrales, and D. González-Gómez, "Physicochemical and bioactive properties evolution during ripening of "Ambrunés" sweet cherry cultivar," LWT-Food Science and Technology, vol. 44, no. 1, pp. 199-205, 2011.

[40] L. Frusciante, P. Carli, M. R. Ercolano et al., "Antioxidant nutritional quality of tomato," Molecular Nutrition \& Food Research, vol. 51, no. 5, pp. 609-617, 2007.

[41] D. Aslanova, E. Bakkalbasi, and N. Artik, "Effect of storage on 5-hydroxymethylfurfural (HMF) formation and color change in jams," International Journal of Food Properties, vol. 13, no. 4, pp. 904-912, 2010. 


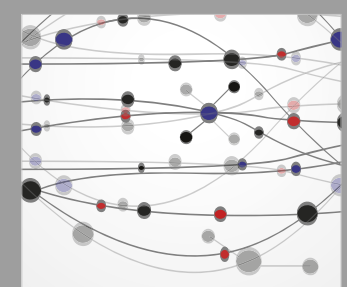

The Scientific World Journal
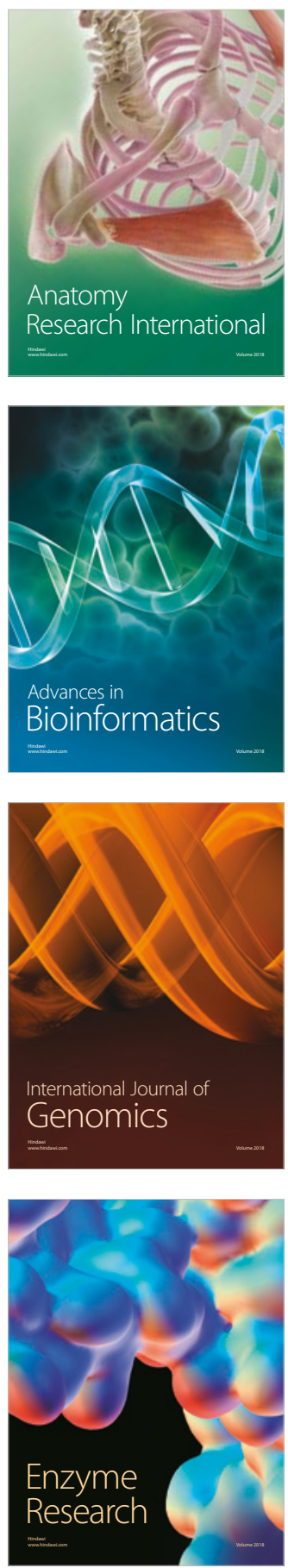
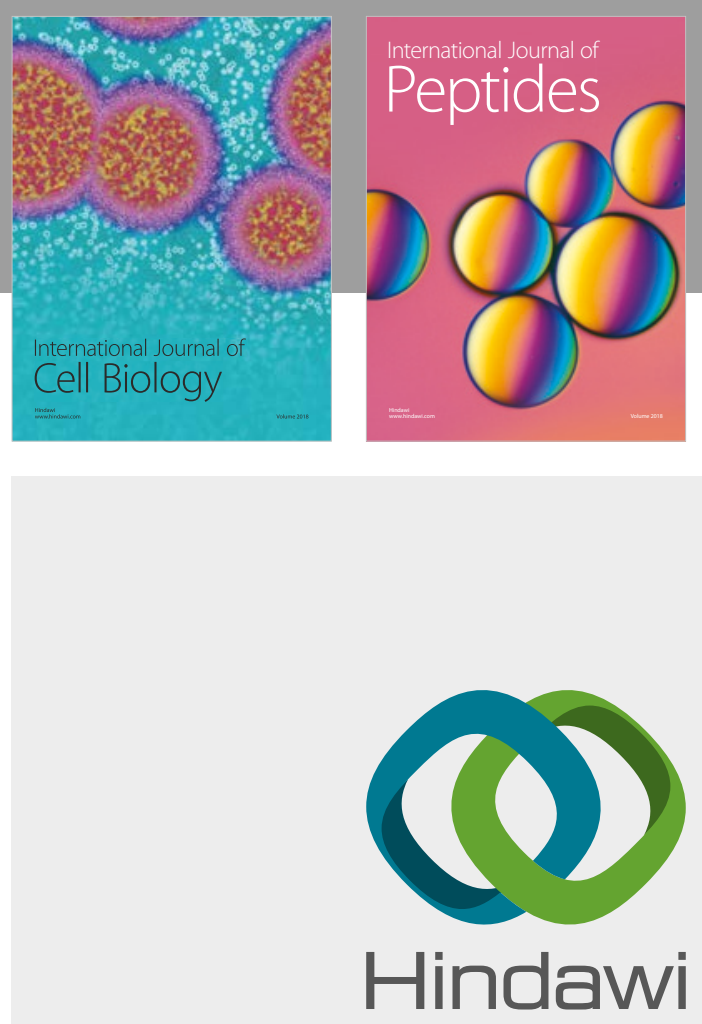

Submit your manuscripts at

www.hindawi.com
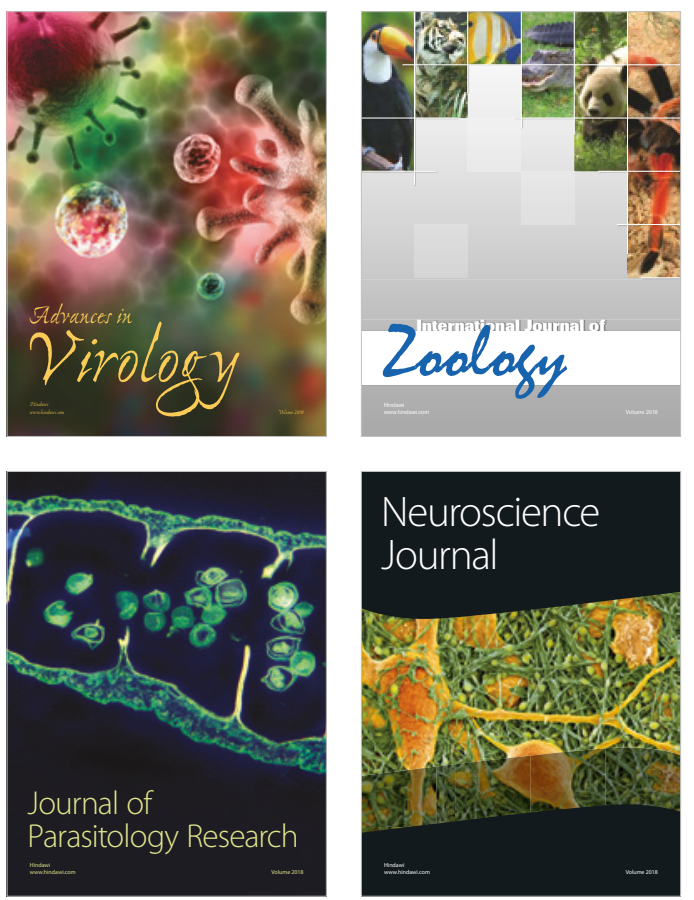
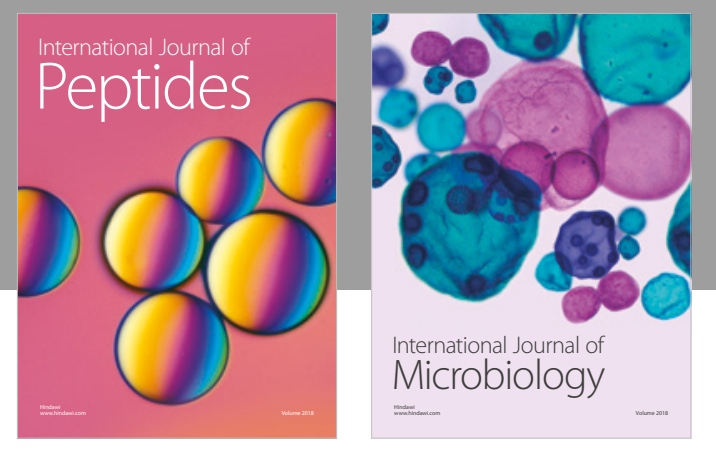

nternational Journal of Microbiology
Journal of
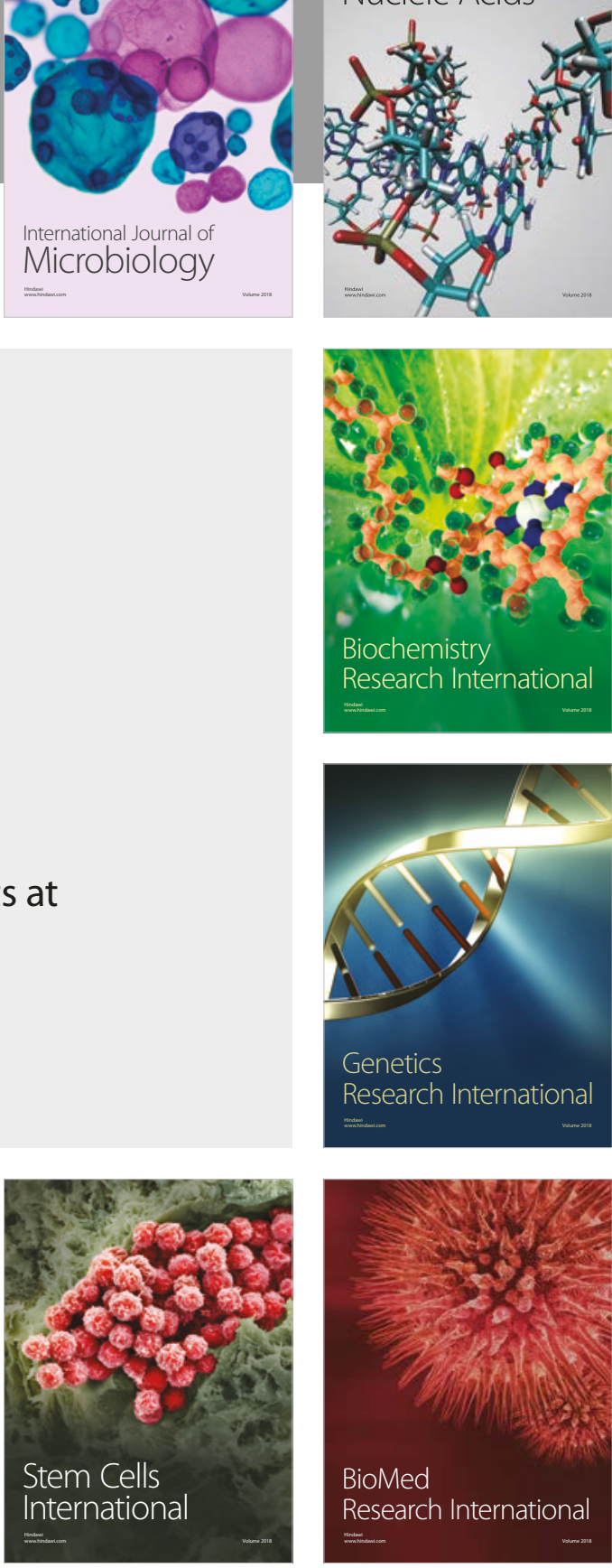
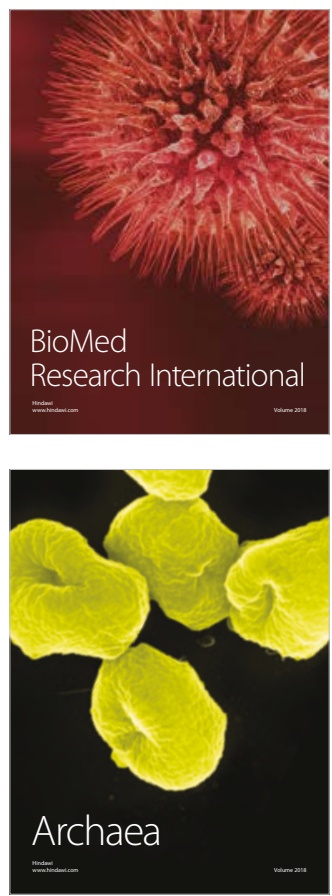